\title{
A Segmented Logistic Regression Approach to Evaluating Change in Caesarean Section Rate with Reform of Birth Planning Policy in Two Regions in China from 2012 to 2016
}

This article was published in the following Dove Press journal: Risk Management and Healthcare Policy

Lili Kang, ${ }^{1,2, *}$ Shangyuan Ye, (D) ${ }^{3, *}$ Kangzhen Jing, ${ }^{4}$ Yancun Fan, ${ }^{2}$ Qihui Chen, (D) ${ }^{5}$ Ning Zhang, 6,7 Bo Zhang (iD)

'Center for Health Policy and Management Studies, Nanjing University, Nanjing, Jiangsu, People's Republic of China; ${ }^{2}$ School of Health Management, Inner Mongolia Medical University, Hohhot, Inner Mongolia, People's Republic of China; ${ }^{3}$ Department of Population Medicine, Harvard Pilgrim Health Care Institute and Harvard Medical School, Boston, MA, USA; ${ }^{4}$ Department of Medical Affair, Nanjing Drum Tower Hospital, The Affiliated Hospital of Nanjing University Medical School, Nanjing, Jiangsu, People's Republic of China; ${ }^{5}$ Center for Food and Health Economic Research, College of Economics and Management, China Agricultural University, Beijing, People's Republic of China; ${ }^{6}$ Department of Health Policy and Management, School of Public Health and Health Sciences, University of Massachusetts, Amherst, MA, USA; ${ }^{7}$ Meyers Primary Care Institute, $A$ Joint Endeavor of University of Massachusetts Medical School, Reliant Medical Group, and Fallon Health, Worcester, MA, USA; ${ }^{8}$ Department of Neurology and ICCTR Biostatistics and Research Design Center, Boston Children's Hospital and Harvard Medical School, Boston, MA, USA

*These authors contributed equally to this work

Correspondence: Bo Zhang; Shangyuan Ye

Email bo.zhang@childrens.harvard.edu; shangyuan_ye@harvardpilgrim.org
Objective: This study evaluated change in caesarean section rate with reform of birth planning policy in China from one-child to two-child policy.

Methods: Study data were collected from patient-level hospital records of 59,668 pregnant women who visited three major urban hospitals in Jiangsu Province and Inner Mongolia Autonomous Region of China between January 2012 and December 2016. A segmented logistic regression approach was developed to evaluate the changes in caesarean section rate in these regions with the launch of China's new partial and universal two-child policies in January 2014 and January 2016, respectively.

Results: Jiangsu Province had a significantly lower non-emergency caesarean rate (Jiangsu $8.15 \%$ vs Inner Mongolia $34.03 \%, p<0.001)$ and a much lower percentage of minority population (Jiangsu $6.99 \%$ vs Inner Mongolia $21.76 \%, p<0.001$ ) than Inner Mongolia Autonomous Region. In Jiangsu Province, no change in caesarean section rate was detected with the two-child policies (all $p$-values $>0.05$ ), although the unadjusted trend change (0.038, 95\% confidence interval or CI: [0.016, 0.060], $p<0.001)$ in log odds after the implementation of the partial two-child policy was statistically significant. In Inner Mongolia Autonomous Region, an immediate jump in caesarean section rate was discovered by the segmented logistic regression with the implementation of both the partial (unadjusted level change 0.297, CI: [0.105, 0.489], $p=0.002$ ) and universal two-child policies (unadjusted level change 1.945, CI: [1.277, 2.614], $p<0.001)$; but the rate reverted to the previous level thereafter. Ethnicity, maternal age, maternal reproduction history, insurance coverage type, infant weight, and infant gender were the significant factors associated with caesarean section rate (for odds ratios, all $p$-values $<0.05$ ). However, the significance of infant gender may stem from the large sample size of the study and is not clinically meaningful.

Conclusion: Change in caesarean section rate was not observed with the launch of twochild policy in China.

Keywords: one-child policy, two-child policy, caesarean section, segmented logistic regression

\section{Introduction}

In 1979, China introduced a national birth planning policy that limited all families to having only one child, known as the one-child policy. This policy was officially relaxed nationwide in $2014,{ }^{1}$ a reform that has been highly significant for its impact on healthcare for families who, for the first time in three decades, are no longer 
restricted to one child. Several studies have documented the impacts on fertility, family birth planning, and health behaviors. $^{2}$ In the decades prior to the 2014 reform, the one-child policy was criticized for ethical issues in family birth planning. One such criticism is that it misled the practice of maternal care in China, such as the overuse of caesarean section. ${ }^{3-8}$

Caesarean section refers to the use of surgical procedure to deliver one or more babies. Caesarean section for non-medical reasons at term may increase risk of morbidity or mortality for the mother and cause problems in subsequent pregnancies, including uterine scar rupture and a greater risk of stillbirth and neonatal morbidity. ${ }^{9-13}$ The caesarean section rate in China peaked at 54.6\% in 2011 and then stabilized at $35 \%$ thereafter. $^{13,14}$ The reasons for such high rates under the onechild policy are complex and have been studied in the literature. $^{3-8,10-15}$ Zhang et $\mathrm{al}^{4}$ and Feng et $\mathrm{al}^{5}$ argued that under the one-child policy, some pregnant women and their family members requested a caesarean section delivery to ensure that they would give birth on a particular lucky day on the astrological calendar. Due to the lack of comprehensive knowledge on the adverse effects of caesarean sections, some women and their families requested caesarean section because they believed that planned caesarean section was safer for both the baby and the mother. ${ }^{16}$

The two-child policy was implemented in two phases. After the termination of the one-child policy, the partial twochild policy was implemented in January 2014, stipulating that families could have two children if either parent was the only child of their parents. Then, in January 2016, the universal two-child policy was announced and implemented nationwide, allowing all Chinese couples to have two children unconditionally. ${ }^{17-19}$ A recent study showed that approximately $25 \%$ of young female adults of childbearing age who had a first birth gave birth to a second child after the launch of the two-child policy. ${ }^{20}$ Obstetricians and gynecologists may consequently encounter challenges arising from patients who request repeated caesarean sections and their subsequent medical complications. In this study, we developed a segmented logistic regression analysis ${ }^{21}$ to examine whether there was any change in caesarean section rate in China along with the launch of the two-child policy.

\section{Methods}

\section{Study Design}

This study was designed to retrospectively extract the electronic health records of pregnant women who, between
January 2012 and December 2016, were admitted to and gave birth in three major urban hospitals, one in Jiangsu Province and two in Inner Mongolia Autonomous Region. The Nanjing Drum Tower Hospital in Jiangsu Province is affiliated with the Nanjing University Medical School in Nanjing, the capital city of Jiangsu, and is equipped with 125 beds and staffed by 186 professionals, including obstetricians and nurses. The Maternal and Children Health Hospital of Inner Mongolia is a first-tier maternal and childcare hospital in Hohhot, the capital city of Inner Mongolia, and is equipped with 121 beds and staffed by 900 obstetricians and other health professionals. The second hospital in Inner Mongolia is the General Hospital of Xilin Gol City, located in the central area of Inner Mongolia, and is equipped with 36 beds and staffed by 40 obstetricians and professionals. This study was approved by the ethics committee of Inner Mongolia Medical University and conforms to the provisions of the Declaration of Helsinki. For the reason that this study posed no more than minimal risk to study participants, the ethical committee approved a request to waive of the required informed consent under the circumstance that only the unidentified data were obtained for the study for the secondary analysis. Data use in this study was approved by the Institutional Review Boards from the Nanjing Drum Tower Hospital, the Maternal and Children Health Hospital of Inner Mongolia, and the General Hospital of Xilin Gol City.

\section{Study Data}

The study data, extracted from 76,288 patient-level electronic health records from the three hospitals, included mode of delivery of a patient, maternal baseline characteristics at the time of hospital admission, and information on the newborn. To strengthen the validity of our study, 9531 duplicated records or records with missing information were excluded, and an additional 7089 records from patients who underwent emergency caesarean sections were excluded because emergency caesarean section rates were unlikely to be affected by the new nationwide two-child birth planning policy. The final study dataset contained the electronic health records from a total of 59,668 patients who gave birth in the three hospitals, with 18,659 from Jiangsu and 41,009 from Inner Mongolia.

The primary outcome variable of the study was the delivery mode, with two categories: planned caesarean section and vaginal delivery. We conducted a segmented logistic regression analysis to investigate the change in caesarean section rates in the two provinces with the reform of birth planning policies in China. During the study period, there 
were two time points at which China reformed its birth planning policies: the partial two-child policy was launched in January 2014 and the universal two-child policy was launched in January 2016. Other covariates in our study included the patient characteristics of maternal age, maternal ethnicity (Han or minority; "Han Chinese" or "Han ethnic group" refers to an East Asian ethnic majority group and nation native to China), reproductive history (first-time mother or others), type of health insurance coverage (not insured, new rural cooperative medical scheme, or urban health insurance schemes), infant gender (male or female), and infant weight $(<2500 \mathrm{~g}, 2500-3999 \mathrm{~g}$, or $>4000 \mathrm{~g}$ ).

\section{Statistical Analysis}

The baseline characteristics of the study subjects were summarized for all subjects and for the subjects from Jiangsu and Inner Mongolia separately. Groups were compared by Pearson's chi-squared test on categorical variables (mode of delivery, maternal ethnicity, health insurance coverage, reproduction history, and infant gender) and $t$-test on continuous variables (maternal age and infant weight). Since the two-child policy was launched in two steps, the study period can be divided into three phases: one-child policy period (January 2012-December 2013), partial two-child policy period (January 2014-December 2015), and universal twochild policy period (January 2016-December 2016). Segmented logistic regression models ${ }^{21}$ were used to evaluate the effects of the new two-child policy on caesarean section rates. To measure the effect of the implementation of the two-child policy, four covariates were used: two policy period indicators (for the partial two-child policy and universal two-child policy) to examine the change in intercepts after each of the policy implementations, and two interaction terms between time and policy periods to measure the change in slopes between two consequent phases. Given the different child policies between these two provinces, we first evaluated the unadjusted effect of the two-child policy on caesarean section rate for Jiangsu and Inner Mongolia separately. We considered the subjects from Jiangsu and Inner Mongolia separately, and the model can be written as:

$$
\begin{aligned}
\log \left[\frac{P\left(Y_{i}=1\right)}{1-P\left(Y_{i}=1\right)}\right]= & \beta_{0}+\beta_{1} T_{i}+\beta_{2} X_{i}^{(1)}+\beta_{3} X_{i}^{(2)} \\
& +\beta_{4}\left(T_{t}-t_{1}\right) X_{i}^{(1)} \\
& +\beta_{5}\left(T_{t}-t_{2}\right) X_{i}^{(2)}
\end{aligned}
$$

where $Y_{i}$ is an indicator for caesarean section $\left(Y_{i}=1\right)$ versus vaginal delivery $\left(Y_{i}=0\right)$ for subject $i$; $T_{i}$ is the birth time (year) from the beginning of the study (January 2012); $X_{i}^{(1)}$ and $X_{i}^{(2)}$ are binary indicators for the partial and universal two-child policy periods, respectively; $t_{1}$ and $t_{2}$ are the time points of the implementation of the partial and universal twochild policy, respectively; coefficient $\beta_{0}$ represents the initial level of the log odds of caesarean section in the target province; and $\beta_{1}$ is the slope or equivalently the trend of the log odds of caesarean section before the implementation of the partial two-child policy in the target province. The coefficients $\beta_{2}$ and $\beta_{3}$ represent the change in the level of the log odds of caesarean section immediately after the implementation of the partial and universal two-child policies, respectively, in the target province; and $\beta_{4}$ and $\beta_{5}$ represent the change in the trend (slope) of the log odds of caesarean section immediately after the implementation of the partial and universal two-child policies in the target province, respectively.

In addition to the above model, we also considered another segmented logistic regression model including maternal ethnicity, maternal age, health insurance coverage, infant weight, infant gender, and reproductive history to adjust for these covariates. The models with or without covariate adjustments were separately applied to the 18,659 subjects from Jiangsu and 41,009 subjects from Inner Mongolia to evaluate the change in caesarean section rate with the two-child policies in both regions.

We then compared the change in caesarean section rate with the two-child policies between the two provinces. The following model was fit:

$$
\begin{aligned}
\log \left[\frac{P\left(Y_{i}=1\right)}{1-P\left(Y_{i}=1\right)}\right]= & \beta_{0}+\beta_{1} T_{i}+\beta_{2} X_{i}^{(1)}+\beta_{3} X_{i}^{(2)} \\
& +\beta_{4}\left(T_{t}-t_{1}\right) X_{i}^{(1)}+\beta_{5}\left(T_{t}-t_{2}\right) X_{i}^{(2)} \\
& +\beta_{6} G_{i}+\beta_{7} G_{i} T_{i}+\beta_{8} G_{i} X_{i}^{(1)}+\beta_{9} G_{i} X_{i}^{(2)} \\
& +\beta_{10} G_{i}\left(T_{i}-t_{1}\right) X_{i}^{(1)}+\beta_{11} G_{i}\left(T_{i}-t_{2}\right) X_{i}^{(2)}
\end{aligned}
$$

where $Y_{i}$ is an indicator of planned caesarean section for patient $i$; $T_{i}$ is the duration from the beginning of the study to birth; $X_{i}^{(1)}$ and $X_{i}^{(2)}$ are binary indicators for the partial and universal two-child policy periods, respectively; $t_{1}$ and $t_{2}$ are the time points of the implementation of the partial and universal two-child policies, respectively; $G_{i}$ is the group indicator of Jiangsu $\left(G_{i}=1\right)$ versus Inner Mongolia $(G=0)$; coefficient $\beta_{0}$ represents the initial level of the log odds of caesarean section in Inner Mongolia; $\beta_{1}$ is the slope of the $\log$ odds of caesarean section before the implementation of the partial two-child policy in Inner Mongolia; $\beta_{2}$ and $\beta_{3}$ represent the change 
in the level of the log odds of caesarean section immediately after the implementation of the partial and universal two-child policies, respectively, in Inner Mongolia; $\beta_{4}$ and $\beta_{5}$ represent the change in the trend of the log odds of caesarean section immediately after the implementation of the partial and universal two-child policies, respectively, in Inner Mongolia; coefficient $\beta_{6}$ represents the difference in the level of the log odds of caesarean section between Jiangsu and Inner Mongolia during the one-child policy period; $\beta_{7}$ represents the difference in the slope or trend of the log odds of caesarean section between Jiangsu and Inner Mongolia during the one-child policy period; $\beta_{8}$ and $\beta_{9}$ indicate the difference between Jiangsu and Inner Mongolia in the level change of the log odds of caesarean section immediately after the implementation of partial and universal two-child policies, respectively; and $\beta_{10}$ and $\beta_{11}$ represent the difference between Jiangsu and Inner Mongolia in the trend change of the log odds of caesarean section after the implementation of the partial and universal two-child policies, respectively.

We also considered the above model including maternal ethnicity, maternal age, health insurance coverage, infant weight, infant gender, and reproductive history to compare the effect of the two-child policy on caesarean section rates between the two provinces by adjusting for these covariates. Statistical analyses were performed in the $R$ statistical environment ( $R$ version 3.5.1, (C) 2018 The R Foundation for Statistical Computing Platform).

\section{Results}

The numbers and percentages of study subjects are summarized in Table 1 by delivery mode and other characteristics in the full sample and in the samples from Jiangsu Province and Inner Mongolia Autonomous Region, respectively. Jiangsu Province had a lower nonemergency caesarean rate $(8.15 \%$ vs $34.03 \%, p<0.001)$ than Inner Mongolia, a lower percentage of minority population $(6.99 \%$ vs $21.76 \%, p<0.001)$, a lower percentage of male newborns $(51.94 \%$ vs $56.20 \%, p<0.001)$, and a higher percentage of first-time mothers $(81.41 \%$ vs $77.30 \%, p<0.001)$. Average maternal age was 28.91 years old (standard deviation or SD: 4.29), 28.41 years old (SD: 3.74), and 29.14 years old (SD: 4.50) in the full sample, Jiangsu, and Inner Mongolia, respectively $(p<$ 0.001 when comparing the two provinces in maternal age). Average infant weight was $3321 \mathrm{~g}$ (SD: 517), 3298 $\mathrm{g}$ (SD: 517), and $3331 \mathrm{~g}$ (SD: 516) in the full sample, Jiangsu, and Inner Mongolia, respectively $(p<0.001$ when comparing the two provinces in infant weight). The health insurance coverage was also significantly different between the two provinces $(p<0.001)$.

Figure 1 shows the scatterplot of monthly caesarean section rates and their segmented nonparametric regression curves given by the locally estimated scatterplot smoothing (LOESS) of the two provinces in three birth planning phases from January 2012 to December 2016: the onechild policy phase (months 1-24), the partial two-child policy phase (months 25-48), and the universal two-child policy phase (months 49-60). Figure 1 demonstrated that the trajectories of the caesarean section rates in the two provinces followed different patterns. Overall, Jiangsu had a much lower caesarean section rate than Inner Mongolia, but the difference was reduced at the end of study period. Followed by an immediate jump of an estimated 3.665\% after the one-child policy phase, an increasing trend in caesarean section rate was observed for Jiangsu during the partial two-child policy phase. The caesarean section rate for Inner Mongolia presented a constantly decreasing trend during the study period, with an immediate drop of an estimated $2.164 \%$ at the beginning of the partial twochild policy phase. During the universal two-child policy phase, with no obvious immediate change observed after the policy implementation, the caesarean section rate increased in Jiangsu. A large unusual jump of an estimated $12.258 \%$ was observed in Inner Mongolia; however, the rate reverted to the decreasing track after 3 months.

Table 2 shows the estimates of coefficients and their $95 \%$ CIs in segmented logistic regression models on caesarean section with and without covariate adjustment for Jiangsu and Inner Mongolia, respectively, for detecting changes after the launch of the partial and universal two-child policies. Characterized by four regression coefficients are the level change in log odds of caesarean section with the partial twochild policy, the trend change in log odds of caesarean section with the partial two-child policy, the level change in log odds of caesarean section with the universal two-child policy, and the trend change in log odds of caesarean section with the universal two-child policy. For Jiangsu, only the unadjusted trend change after the implementation of the partial two-child policy was statistically significant $\left(\beta_{4}=0.038\right.$, CI: [0.016, $0.060], p<0.001)$, but the significance vanished when it was adjusted by other covariates $\left(\beta_{4}=0.020, \mathrm{CI}\right.$ : [ $\left.-0.002,0.042\right]$, $p=0.078$ ). In contrast, the level and trend changes in log odds of caesarean section were all statistically significant for Inner Mongolia (all $p$-values $<0.01$ ), although the trend change with the universal two-child policy was dismissed at a significant 
Table I Numbers (Percentages in Parentheses) of Subjects by Delivery Mode and Other Characteristics in Full Sample and in Jiangsu and Inner Mongolia

\begin{tabular}{|c|c|c|c|c|}
\hline & $\begin{array}{l}\text { Full sample } \\
n=59,668\end{array}$ & $\begin{array}{l}\text { Jiangsu } \\
n=18,659\end{array}$ & $\begin{array}{l}\text { Inner Mongolia } \\
n=41,009\end{array}$ & $p$-value \\
\hline $\begin{array}{l}\text { Delivery mode } \\
\text { Vaginal } \\
\text { Caesarean section }\end{array}$ & $\begin{array}{l}44,190(74.06 \%) \\
15,478(25.94 \%)\end{array}$ & $\begin{array}{l}17,139(91.85 \%) \\
1520(8.15 \%)\end{array}$ & $\begin{array}{l}27,05 \mid(65.97 \%) \\
\mid 3,958(34.03 \%)\end{array}$ & $<0.001$ \\
\hline $\begin{array}{l}\text { Maternal ethnicity } \\
\text { Han } \\
\text { Minority }\end{array}$ & $\begin{array}{l}49,437(82.85 \%) \\
10,23 \mid(17.15 \%)\end{array}$ & $\begin{array}{l}\text { I7,354 (93.0|\%) } \\
\text { I305 (6.99\%) }\end{array}$ & $\begin{array}{l}32,083(78.23 \%) \\
8926(21.76 \%)\end{array}$ & $<0.001$ \\
\hline $\begin{array}{l}\text { Maternal age (years) } \\
\quad<20 \\
20-24 \\
25-29 \\
30-34 \\
\geq 35\end{array}$ & $\begin{array}{l}303(0.51 \%) \\
6884(11.54 \%) \\
30,158(50.59 \%) \\
15,735(26.37 \%) \\
656 \mid(10.99 \%)\end{array}$ & $\begin{array}{l}60(0.32 \%) \\
2126(11.39 \%) \\
10,368(55.56 \%) \\
4813(25.79 \%) \\
1292(6.92 \%)\end{array}$ & $\begin{array}{l}243(0.59 \%) \\
4758(11.60 \%) \\
19,817(48.32 \%) \\
10,922(26.63 \%) \\
5269(12.84 \%)\end{array}$ & $<0.001$ \\
\hline $\begin{array}{l}\text { Insurance coverage } \\
\text { Not insured } \\
\text { UHIS } \\
\text { NCMS }\end{array}$ & $\begin{array}{l}18,449(30.92 \%) \\
13,185(22.10 \%) \\
28,034(46.98 \%)\end{array}$ & $\begin{array}{l}6,620(35.48 \%) \\
12,039(64.52 \%) \\
0(0.00 \%)\end{array}$ & $\begin{array}{l}\text { II,829 (28.84\%) } \\
\text { II } 46(2.79 \%) \\
28,034(68.36 \%)\end{array}$ & $<0.001$ \\
\hline $\begin{array}{l}\text { Infant weights }(g) \\
\quad<2500 \\
2500-4000 \\
>4000\end{array}$ & $\begin{array}{l}\text { II,694 (5.23\%) } \\
31,778(86.28 \%) \\
|8,43|(8.49 \%)\end{array}$ & $\begin{array}{l}\text { I04I (5.57\%) } \\
\text { I6,504 (88.45\%) } \\
\text { III4 (5.97\%) }\end{array}$ & $\begin{array}{l}2077(5.06 \%) \\
34,978(85.29 \%) \\
3954(9.64 \%)\end{array}$ & $<0.001$ \\
\hline $\begin{array}{l}\text { Infant gender } \\
\text { Male } \\
\text { Female }\end{array}$ & $\begin{array}{l}32,739(54.87 \%) \\
26,929(45.13 \%)\end{array}$ & $\begin{array}{l}9692(51.94 \%) \\
8967 \text { (48.06\%) }\end{array}$ & $\begin{array}{l}23,047(56.20 \%) \\
17,962(43.80 \%)\end{array}$ & $<0.001$ \\
\hline $\begin{array}{l}\text { Reproductive history } \\
\text { First-time mother } \\
\text { Others }\end{array}$ & $\begin{array}{l}46,893(78.59 \%) \\
12,755(2 \mid .41 \%)\end{array}$ & $\begin{array}{l}|5,| 9 \mid(8|.4| \%) \\
3468 \text { (I8.59\%) }\end{array}$ & $\begin{array}{l}31,702(77.30 \%) \\
9307(22.70 \%)\end{array}$ & $<0.001$ \\
\hline
\end{tabular}

Note: $p$-values: testing difference between two provinces in baseline characteristics.

Abbreviation: UHIS, Urban Health Insurance Schemes; NCMS, New Rural Cooperative Medical Scheme.

level of 0.05 when it was adjusted by other covariates $\left(\beta_{5}=\right.$ $-0.013, \mathrm{CI}:[-0.026,0.000], p=0.056)$. Table 3 presents the differences in the initial phase and in level and trend changes in $\log$ odds of caesarean section, with $95 \%$ CIs, between Inner Mongolia and Jiangsu Province with and without covariate adjustment. These differences were characterized by the coefficients from the segmented logistic regression for twoprovince comparison. Taking Inner Mongolia as the reference, the immediate unadjusted level changes for Jiangsu Province after the implementation of the new two-child policies were significantly lower $\left(\beta_{8}=-0.537, \mathrm{CI}:[-1.068,-0.006], p=\right.$ 0.048 and $\beta_{9}=-3.340, \mathrm{CI}:[-5.020,-1.673], p<0.001$, respectively). The unadjusted trend changes following the two-child policies were significantly higher $\left(\beta_{10}=0.049, \mathrm{CI}\right.$ : [0.027, 0.072], $p<0.001$ and $\beta_{11}=0.057$, CI: [0.025, 0.088], $p<0.001$, respectively) for Jiangsu Province. The adjusted differences between the two provinces are close to the unadjusted differences.

Table 4 shows the odds ratios (OR) of caesarean section and their $95 \%$ confidence intervals given by other covariates in the segmented logistic regression conducted for Jiangsu, Inner Mongolia, and comparison between the two provinces. Ethnicity, maternal age, insurance coverage type, and infant weight are common significant factors of caesarean section for Jiangsu and Inner Mongolia (all $p$-values < 0.05). However, the significance of infant gender may stem from the large sample size of the study and is not clinically meaningful. Maternal reproductive history is significant for Jiangsu $(\mathrm{OR}=4.788, \mathrm{CI}:[4.164,5.511], p<0.001)$ but not for Inner Mongolia (OR=1.011, CI: [0.974, 1.069], $p=0.706)$. 


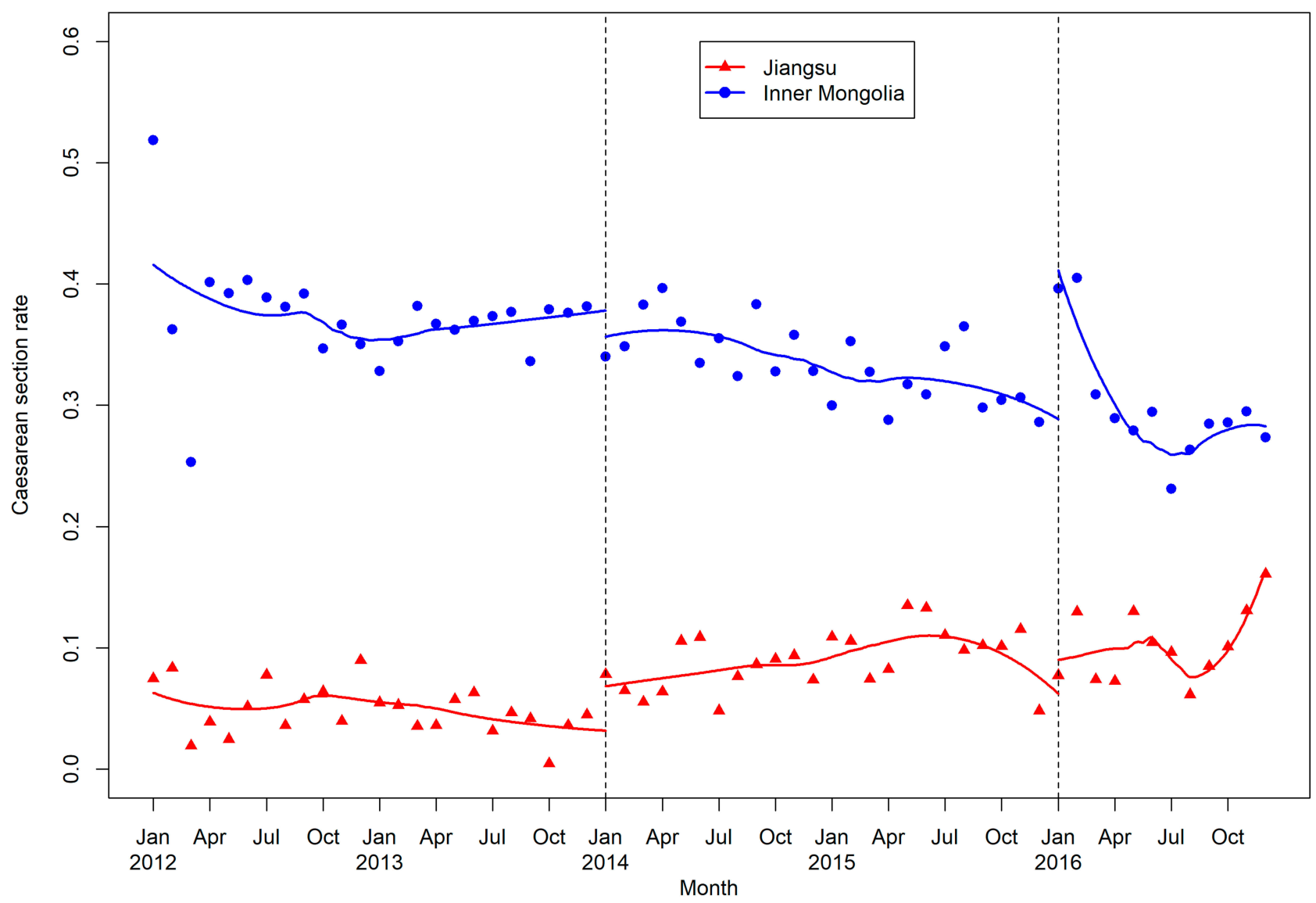

Figure I Scatterplots of monthly caesarean section rates in Jiangsu and Inner Mongolia between 2012 and 2016 by month. Solid curves are segmented locally estimated scatterplot smoothing (LOESS) curves; dashed vertical lines denote the time points at which the partial and universal two-child policies were launched.

\section{Discussion}

In this study, we demonstrated two segmented logistic regression models and evaluated how the caesarean section rate changed in Jiangsu and Inner Mongolia with the reform of China's birth planning policy from January 2012 to December 2016. For Jiangsu, there was no detected change in caesarean section rate with the two-child policies. For Inner Mongolia, an immediate increase in caesarean section rate was observed with the implementation of both the partial and universal two-child policies, but the rate reverted to its previous level thereafter. Therefore, we conclude that the two-child policies did not alter the caesarean section rate in either Jiangsu or Inner Mongolia. Ethnicity, maternal age, insurance coverage type, infant weight, infant gender, and maternal reproduction history were the significant factors associated with caesarean section rate; however, the significance of infant gender may not be clinically meaningful and stemmed from the large sample size of the study.

Previous studies reported that the high caesarean section rate in China was associated with a number of socioeconomic and cultural factors. ${ }^{23-26}$ It has been shown that the one-child policy had a negative impact on caesarean section rate: pregnant women would request caesarean section delivery to ensure that births occurred on a lucky day on the astrological calendar because they expected no further pregnancies under the one-child policy. ${ }^{5,6}$ Among these previous studies, Liang et $\mathrm{al}^{2}$ showed a decrease in caesarean section rate with the relaxation of the one-child policy. However, very few data in Liang et $\mathrm{al}^{2}$ were collected from hospitals in western provinces in China, where there are more minority groups. In those areas, situations may be dramatically different. To fill these gaps, we studied the impact of the one-child policy on caesarean section rate using five-year patient-level hospital medical records from three major hospitals in Jiangsu Province and Inner Mongolia Autonomous Region, a province in China with minorities as its majority population. Using the segmented logistic regression models, we also took the full consideration of the two-phase implementation of the two-child policy, and 
Table 2 Estimates of the Coefficients (95\% Confidence Intervals) in Segmented Logistic Regression Models on Caesarean Section Rate with and Without Covariate Adjustment for Jiangsu and Inner Mongolia, Respectively, for Detecting Changes Following the Launch of China's Two-Child Policies

\begin{tabular}{|l|l|l|}
\hline & Unadjusted Coefficients for Jiangsu & Unadjusted Coefficients for Inner Mongolia \\
\hline Initial level $\left(\beta_{0}\right)$ & $-2.732(-2.990,-2.484)^{* * *}$ & $-0.523(-0.600,-0.445)^{* * *}$ \\
Initial trend $\left(\beta_{1}\right)$ & $-0.020(-0.039,-0.002)^{*}$ & $-0.001(-0.006,0.004)$ \\
Level change with partial two-child policy $\left(\beta_{2}\right)$ & $-0.240(-0.735,0.255)$ & $0.297(0.105,0.489)^{* *}$ \\
Trend change with partial two-child policy $\left(\beta_{4}\right)$ & $0.038(0.016,0.060)^{* * *}$ & $-0.01 \mathrm{I}(-0.019,-0.004)^{* *}$ \\
Level change with universal two-child policy $\left(\beta_{3}\right)$ & $-1.395(-2.937,0.132)$ & $1.945(1.277,2.614)^{* * *}$ \\
Trend change with universal two-child policy $\left(\beta_{5}\right)$ & $0.022(-0.007,0.05 \mathrm{I})$ & $-0.034(-0.047,-0.022)^{* * *}$ \\
\hline & Adjusted Coefficients for Jiangsu & Adjusted Coefficients for Inner Mongolia \\
\hline Initial level $\left(\beta_{0}\right)$ & $-2.859(-4.695,-1.636)^{* * *}$ & $-1.284(-1.625,-0.959)^{* * *}$ \\
Initial trend $\left(\beta_{1}\right)$ & $-0.018(-0.037,0.000)$ & $-0.005(-0.010,0.00 \mathrm{I})$ \\
Level change with partial two-child policy $\left(\beta_{2}\right)$ & $-0.385(-0.906,0.135)$ & $0.287(0.090,0.484)^{* *}$ \\
Trend change with partial two-child policy $\left(\beta_{4}\right)$ & $0.020(-0.002,0.042)$ & $-0.010(-0.017,-0.002)^{* *}$ \\
Level change with universal two-child policy $\left(\beta_{3}\right)$ & $-1.257(-2.865,0.336)$ & $0.758(0.067,1.448)^{*}$ \\
Trend change with universal two-child policy $\left(\beta_{5}\right)$ & $0.024(-0.006,0.054)$ & $-0.013(-0.026,0.000)$ \\
\hline
\end{tabular}

Notes: $* 5 \%$ significance; $* * 1 \%$ significance; $* * * 0.1 \%$ significance.

Table 3 Differences in the Initial Phase and in Level and Trend Changes in Log Odds of Caesarean Section (95\% Confidence Intervals) Between Inner Mongolia (Reference) and Jiangsu with and Without Covariate Adjustment

\begin{tabular}{|l|l|l|}
\hline & Unadjusted Difference & Adjusted Difference \\
\hline Initial level difference $\left(\beta_{6}\right)$ & $-2.209(-2.479,-1.949)^{* *}$ & $-1.989(-2.267,-1.721)^{* * *}$ \\
Initial trend difference $\left(\beta_{7}\right)$ & $-0.019(-0.038,-0.000)^{*}$ & $-0.017(-0.036,0.002)$ \\
Level-change difference in log odds with partial two-child policy $\left(\beta_{8}\right)$ & $-0.537(-1.068,-0.006)^{*}$ & $-0.549(-1.087,-0.013)^{*}$ \\
Trend-change difference in log odds with partial two-child policy $\left(\beta_{10}\right)$ & $0.049(0.027,0.072)^{* * *}$ & $0.047(0.024,0.070)^{* * *}$ \\
Level-change difference in log odds with universal two-child policy $\left(\beta_{9}\right)$ & $-3.340(-5.020,1.673)^{* * *}$ & $-2.524(-4.217,-0.844)^{* *}$ \\
Trend-change difference in log odds with universal two-child policy $\left(\beta_{11}\right)$ & $0.057(0.025,0.088)^{* * *}$ & $0.042(0.010,0.074)^{* *}$ \\
\hline
\end{tabular}

Notes: $* 5 \%$ significance; $* * \mid \%$ significance; $* * * 0.1 \%$ significance.

evaluated the differences in caesarean section rate between the two provinces. Our results suggest that the two-child policy did not alter the caesarean section rate in either Jiangsu or Inner Mongolia, though the results from both provinces contradict previous findings that the one-child policy may have contributed to the high rate of caesarean section in China. ${ }^{2}$ Note that the caesarean section rates, before and after the two-child policy was launched, were considerably different between the two provinces. Inner Mongolia had an overall much higher rate of caesarean delivery than Jiangsu. One factor contributing to such a difference may be the gap in criteria for caesarean section between the two provinces. Many studies also show that expanding health insurance coverage from 2010 in China may facilitate the overuse of caesarean section in minority areas ${ }^{6}$ because almost half of the planned caesarean sections were recommended by obstetricians for their financial profit. ${ }^{2,7,8,16}$
There are several limitations in our study. The patientlevel data collected from electronic health records in this study did not include socioeconomic information and clinical characteristics of the patients undergoing caesarean sections for medical reasons. Both sides are associated with planned caesarean sections. In addition, we assessed and compared the changes in caesarean section rate with the two-child policy in one mega province, Jiangsu, and one minority region, Inner Mongolia. Whether our conclusions can be generalized to other areas in China remains unclear.

\section{Conclusion}

We evaluated the change in the caesarean section rate with the new two-child policy in Jiangsu Province and Inner Mongolia Autonomous Region. Our results showed that the new policy did not alter the caesarean section rate in either province, but the caesarean section rates were 
Table 4 Odds Ratios of Caesarean Section (95\% Confidence Intervals) Given by Other Covariates in Jiangsu and Inner Mongolia and in Their Comparison

\begin{tabular}{|c|c|c|c|}
\hline & Odds Ratio for Jiangsu & Odds Ratio for Inner Mongolia & Odds Ratio in comparison \\
\hline $\begin{array}{l}\text { Maternal ethnicity } \\
\text { Han } \\
\text { Minority }\end{array}$ & $\begin{array}{l}\text { Reference } \\
0.650(0.477,0.866)^{* *}\end{array}$ & $\begin{array}{l}\text { Reference } \\
1.251(1.190,1.315)^{* * *}\end{array}$ & $\begin{array}{l}\text { Reference } \\
1.272(1.211,1.335)^{* * *}\end{array}$ \\
\hline $\begin{array}{l}\text { Maternal age (year) } \\
\quad<20 \\
20-24 \\
25-29 \\
30-34 \\
\geq 35\end{array}$ & $\begin{array}{l}\text { Reference } \\
2.868(0.860,17.833) \\
2.847(0.863,17.624) \\
3.427(1.036,21.232)^{*} \\
5.273(1.585,32.747)^{*}\end{array}$ & $\begin{array}{l}\text { Reference } \\
1.294(0.950,1.794) \\
1.585(1.170,2.187)^{* *} \\
2.250(1.658,3.108)^{* * *} \\
3.136(2.301,4.348)^{* * *}\end{array}$ & $\begin{array}{l}\text { Reference } \\
1.357(1.005,1.864)^{*} \\
1.582(1.177,2.165)^{* *} \\
2.220(1.649,3.041)^{* * *} \\
3.162(2.341,4.346)^{* * *}\end{array}$ \\
\hline $\begin{array}{l}\text { Insurance coverage } \\
\text { Not insured } \\
\text { UHIS } \\
\text { NCMS }\end{array}$ & $\begin{array}{l}\text { Reference } \\
0.706(0.628,0.793)^{* * *} \\
-\end{array}$ & $\begin{array}{l}\text { Reference } \\
2.140(1.882,2.434)^{* * *} \\
1.203(1.147,1.263)^{* * *}\end{array}$ & $\begin{array}{l}\text { Reference } \\
0.942(0.865,1.026) \\
\mathrm{I} .124(1.073,1.178)^{* * *}\end{array}$ \\
\hline $\begin{array}{l}\text { Infant weight (g) } \\
\qquad 2500 \\
2500-4000 \\
>4000\end{array}$ & $\begin{array}{l}\text { Reference } \\
0.425(0.355,0.512)^{* * *} \\
0.645(0.499,0.834)^{* * *}\end{array}$ & $\begin{array}{l}\text { Reference } \\
0.926(0.842,1.018) \\
1.203(1.147,1.263)^{* * *}\end{array}$ & $\begin{array}{l}\text { Reference } \\
0.742(0.682,0.808)^{* * *} \\
\mathrm{I} .223(\mathrm{I} .104, \mathrm{I} .354)^{* * *}\end{array}$ \\
\hline $\begin{array}{l}\text { Infant gender } \\
\text { Male } \\
\text { Female }\end{array}$ & $\begin{array}{l}\text { Reference } \\
1.015(0.909,1.134)\end{array}$ & $\begin{array}{l}\text { Reference } \\
\text { I.08I (I.036, I.I29)*** }\end{array}$ & $\begin{array}{l}\text { Reference } \\
1.078(1.036,1.122)^{* * *}\end{array}$ \\
\hline $\begin{array}{l}\text { Reproductive history } \\
\text { First-time mother } \\
\text { Others }\end{array}$ & $\begin{array}{l}\text { Reference } \\
4.788(4.164,5.511)^{* * *}\end{array}$ & $\begin{array}{l}\text { Reference } \\
\text { I.0II }(0.974,1.069)\end{array}$ & $\begin{array}{l}\text { Reference } \\
1.255(1.192,1.322)^{* * *}\end{array}$ \\
\hline
\end{tabular}

Notes: $* 5 \%$ significance; $* * 1 \%$ significance; $* * * 0.1 \%$ significance; - no returned odds ratio due to the absence of data in this category.

Abbreviations: UHIS, Urban Health Insurance Schemes; NCMS, New Rural Cooperative Medical Scheme.

considerably different in the two provinces before and after the launch of the new two-child policy.

\section{Disclosure}

The authors report no conflicts of interest in this work.

\section{References}

1. Hesketh T, Zhu WX. Health in China - The one child family policy: the good, the bad, and the ugly. Br Med J. 1997;314(7095):1685-1687. doi:10.1136/bmj.314.7095.1685

2. Liang J, Mu Y, Li X, et al. Relaxation of the one child policy and trends in caesarean section rates and birth outcomes in China between 2012 and 2016: observational study of nearly seven million health facility births. $B M J$. 2018;360:k817. doi:10.1136/bmj.k817

3. Mi J, Liu FC. Rate of caesarean section is alarming in China. Lancet. 2014;383(9927):1463-1464. doi:10.1016/S0140-6736(14)60716-9

4. Zhang J, Liu Y, Meikle S, Zheng J, Sun W, Li Z. Cesarean delivery on maternal request in southeast China. Obstetrics Gynecol. 2008;111 (5):1077-1082. doi:10.1097/AOG.0b013e31816e349e

5. Feng XL, Xu L, Guo Y, Ronsmans C. Factors influencing rising caesarean section rates in China between 1988 and 2008. Bull World Health Organ. 2012;90(1):30-9, 9A. doi:10.2471/BLT.11.0903 99
6. Klemetti R, Che X, Gao Y, et al. Cesarean section delivery among primiparous women in rural China: an emerging epidemic. $\mathrm{Am}$ J Obstet Gynecol. 2010;202(1):65.e1-65.e6. doi:10.1016/j.ajog.2009. 08.032

7. Sufang G. Delivery settings and caesarean section rates in China. Bull World Health Organ. 2007;85(10):755-762. doi:10.2471/BLT. 00.000000

8. Feng XL, Wang Y, An L, Ronsmans C. Cesarean section in the People's Republic of China: current perspectives. Int $J$ Womens Health. 2014;6:59-74. doi:10.2147/IJWH.S41410

9. Belizán JM, Althabe F, Cafferata ML. Health consequences of the increasing caesarean section rates. Epidemiology. 2007;18 (4):485-486. doi:10.1097/EDE.0b013e318068646a

10. Blustein J, Liu J. Time to consider the risks of caesarean delivery for long term child health. BMJ. 2015;350.

11. O'Neill SM, Agerbo E, Kenny LC, et al. Cesarean section and rate of subsequent stillbirth, miscarriage, and ectopic pregnancy: a Danish register-based cohort study. PLoS Med. 2014;11(7):e1001670. doi:10.1371/journal.pmed.1001670

12. Sevelsted A, Stokholm J, Bønnelykke K, Bisgaard H. Cesarean section and chronic immune disorders. Pediatrics. 2015;135(1):e92-e98. doi:10.1542/peds.2014-0596

13. Rutayisire E, Wu X, Huang K, Tao S, Chen Y, Tao F. Cesarean section may increase the risk of both overweight and obesity in preschool children. BMC Pregnancy Childbirth. 2016;16(1):338. doi:10.1186/s12884-016-1131-5 
14. Xu H, Ding Y, Ma Y, Xin X, Zhang D. Cesarean section and risk of postpartum depression: a meta-analysis. J Psychosom Res. 2017;97:118-126. doi:10.1016/j.jpsychores.2017.04.016

15. Li H-T, Luo S, Trasande L, et al. Geographic variations and temporal trends in cesarean delivery rates in China, 2008-2014. JAMA. 2017;317(1):69-76. doi:10.1001/jama.2016.18663

16. L Y K L, Holroyd E, Ng CY. Exploring factors influencing Chinese women's decision to have elective caesarean surgery. Midwifery. 2001;17(4):314-322. doi:10.1054/midw.2001.0274

17. Zeng Y, Hesketh T. The effects of China's universal two-child policy. Lancet. 2016;388(10054):1930-1938. doi:10.1016/S0140-6736(16) 31405-2

18. Cheng P, Duan T. China's new two-child policy: maternity care in the new multiparous era. BJOG. 2016;123(S3):7-9. doi:10.1111/ bjo.2016.123.issue-S3

19. Liang J, Mu Y, Li X, et al. Relaxation of the one child policy and trends in cesarean section rates and birth outcomes in china between 2012 and 2016: observational study of nearly seven million health facility births. Obstet Gynecol Surv. 2018;73(8):447-449. doi:10.1097/01.ogx.0000544558.91752.20

20. Zhu Y, Zhu C. The second childbirth expectation and employment status: evidence from China Labor-force Dynamics Survey. Stud Labor Econ. 2015;3:110-128.

21. Wagner AK, Soumerai SB, Zhang F, Ross-Degnan D. Segmented regression analysis of interrupted time series studies in medication use research. J Clin Pharm Ther. 2002;27(4):299-309. doi:10.1046/ j.1365-2710.2002.00430.x
22. Tibshirani R, Hastie T. Local likelihood estimation. J Am Stat Assoc. 1987;82(398):559-567. doi:10.1080/01621459.1987.10478466

23. Feng L, Yue Y. Analysis on the 45-year cesarean rate and its social factors. Med Soc. 2002;15:14-16.

24. Tang S, Li X, Wu Z. Rising cesarean delivery rate in primiparous women in urban China: evidence from three nationwide household health surveys. Am J Obstet Gynecol. 2006;195(6):1527-1532. doi:10.1016/j.ajog.2006.03.044

25. Wu WL. Cesarean delivery in Shantou, China: a retrospective analysis of 1922 women. Birth. 2000;27(2):86-90. doi:10.1046/j.1523536x.2000.00086.x

26. Harris A, Gao Y, Barclay L, et al. Consequences of birth policies and practices in post-reform China. Reprod Health Matters. 2007;15 (30):114-124. doi:10.1016/S0968-8080(07)30315-7

27. Wang E. Requests for cesarean deliveries: the politics of labor pain and pain relief in Shanghai, China. Soc Sci Med. 2017;173:1-8. doi:10.1016/j.socscimed.2016.11.032

28. Zhang $\mathrm{Z}, \mathrm{Gu} \mathrm{C}$, Zhu $\mathrm{X}$, et al. Factors associated with Chinese nulliparous women's choices of mode of delivery: a longitudinal study. Midwifery. 2018;62:42-48. doi:10.1016/j.midw.2018.03.013
Risk Management and Healthcare Policy

\section{Publish your work in this journal}

Risk Management and Healthcare Policy is an international, peerreviewed, open access journal focusing on all aspects of public health, policy, and preventative measures to promote good health and improve morbidity and mortality in the population. The journal welcomes submitted papers covering original research, basic science, clinical \& epidemiological studies, reviews and evaluations, guidelines, expert opinion and commentary, case reports and extended reports. The manuscript management system is completely online and includes a very quick and fair peer-review system, which is all easy to use. Visit http://www.dovepress.com/testimonials.php to read real quotes from published authors. 